\title{
Atrieflimmer, fysisk aktivitet og utholdenhetstrening
}

Engelsk oversettelse av hele artikkelen på www.tidsskriftet.no

\section{Sammendrag}

Bakgrunn. Klinisk erfaring og resultater fra enkelte studier kan tyde på at fysisk aktivitet i form av utholdenhetstrening kan påvirke utviklingen av atrieflimmer (AF). Hensikten med denne artikkelen er å se nærmere på kunnskapsgrunnlaget for hypotesen om at det er sammenheng mellom fysisk aktivitet og denne tilstanden.

Materiale og metode. Denne oversiktsartikkelen er basert på søk i PubMed på spesifikke søkeord avgrenset til perioden 1995-mars 2011. Vi fant 17 enkeltstudier og tre relativt nye oversiktsartikler. Hver artikkel ble lest av minst to av forfatterne og deretter diskutert. Sju av enkeltstudiene var uegnet til å belyse vår problemstilling, vi omtaler derfor de resterende ti.

Resultater. Det finnes støtte for hypotesen om at planmessig utholdenhetstrening med høy intensitet, slik som løping, kan gi økt risiko for atrieflimmer. Det er ingen holdepunkter for at mindre intens fysisk aktivitet, slik som det å gå, øker risikoen. Flere av studiene har metodologiske svakheter.

Fortolkning. Viktige spørsmål er ubesvart. Det er behov for flere studier som kan belyse sammenhengen mellom graden av treningsintensitet, samlet volum av intens utholdenhetstrening, aldersforandringer og atrieflimmer, og det trengs studier hvor kvinner er med.

\section{Sidsel Graff-Iversen} sgri@fhi.no

Divisjon for epidemiologi Nasjonalt folkehelseinstitutt og

Institutt for samfunnsmedisin Universitetet i Tromsø

\section{Knut Gjesdal}

Kardiologisk avdeling

Oslo universitetssykehus, Ullevål

\section{Astanand Jugessur}

Divisjon for epidemiologi

Nasjonalt folkehelseinstitutt og

Craniofacial Research

Murdoch Children's Research Institute Royal Children's Hospital

Parkville, Australia

\section{Marius Myrstad}

Medisinsk avdeling

Diakonhjemmet Sykehus

Wenche Nystad

Divisjon for epidemiologi

Nasjonalt folkehelseinstitutt

\section{Randi Selmer}

Divisjon for epidemiologi

Nasjonalt folkehelseinstitutt

\section{Dag S. Thelle}

Avdeling for biostatistikk

Institutt for medisinske basalfag

Universitetet i Oslo

Innen miljøer for langdistanseløp og blant kardiologer har man lenge hatt inntrykk av at utvikling av atrieflimmer (AF) kan være knyttet til langvarig fysisk trening. I denne artikkelen tar vi for oss publiserte artikler som kan belyse spørsmålet om hvorvidt fysisk aktivitet $\mathrm{i}$ form av lett eller moderat intens fysisk aktivitet eller som planmessig utholdenhetstrening med høy intensitet kan øke risikoen for atrieflimmer.

Atrieflimmer er karakterisert ved uregelmessige sammentrekninger i atriene med en frekvens på 350-480 per minutt (1). Bare en del av impulsene kommer gjennom ledningssystemet til ventriklene fordi AV-knuten fungerer som filter, og i EKG vil QRSkompleksene komme med uregelmessige mellomrom. Atrieflimmer kan komme i anfall eller være permanent. Den perifere pulsfrekvensen vil som regel være raskere enn normalt både i hvile og ved anstrengelse. Hos noen kommer flimmeranfallene helst om natten eller etter måltider, hos andre kommer de under fysisk eller mental belastning. Hos de fleste er imidlertid slike mønstre ikke tydelige. Fra 1950-årene har man brukt begrepet «atrieflimmer uten annen kardiovaskulær sykdom» (lone atrial fibrillation, LAF) der man ikke kjenner til annen hjerteeller stoffskiftesykdom.

Totalt anslås forekomsten av atrieflimmer i vestlige land til $1-2 \%$ av befolkningen (1). Forekomsten øker med alderen, fra $<0,5 \%$ ved 40-50 års alder til 5-15\% ved 80 år, den er noe høyere hos menn enn hos kvinner og har økt de siste tiårene (1). Det antas at omkring 65000 nordmenn er rammet av atrieflimmer, og at 20 000-25000 av disse er under 67 år (2). I en norsk undersøkelse fra 2008 var forekomsten $10 \%$ blant 75 -åringer i Asker og Bærum (3). Etablerte risikofaktorer for atrieflimmer er, foruten alder og kjønn, underliggende hjertesykdom, kronisk lungesykdom, stoffskifteforstyrrelser, hypertensjon, diabetes, overvekt, søvnapné og kronisk nyresykdom (1).

Som viktige faktorer i sykdomsutviklingen regnes strukturelle endringer i hjertet, spesielt $\mathrm{i}$ atriemuskulaturen, endringer $\mathrm{i}$ elektrofysiologiske mekanismer og genetisk disposisjon (1). Strukturelle endringer kan innebære fibrose, inflammasjon, nekrose, hypertrofi og mikrovaskulære forandringer. Når atrieflimmer først opptrer, vil tilstanden i seg selv påvirke myokard i retning av å øke flimmertendensen. Ved paroksystisk atrieflimmer starter det enkelte anfallet oftest fra fokuser i eller nær overgangen mellom lungevenene og venstre atrium, ved persisterende atrieflimmer vedlikeholdes impulsene på grunn av generelle forandringer $\mathrm{i}$ atriene. De siste årene har genetisk forskning bidratt til å identifisere en rekke polymorfismer forbundet med atrieflimmer. Spesielt er arvelig disposisjon av betydning når tilstanden opptrer i ung alder (1).

Komplikasjonene til atrieflimmer er nedsatt livskvalitet og arbeidskapasitet, økt døde-

\section{Hovedbudskap}

- Utholdenhetstrening med relativt høy intensitet gjennom mange år gir trolig $ø$ kt risiko for atrieflimmer, i det minste hos menn over 40 år

- Mindre intens mosjon gir neppe økt risiko for atrieflimmer

- Mange studier av fysisk aktivitet og atrieflimmer har store metodesvakheter 
Tabell 1 Fysisk aktivitet og atrieflimmer i kohortstudier

Studie (førsteforfatter, år)

Aizer A, 2009 (10):

Selektert utvalg hjertefriske leger i alder 40-84 år ( $n=16$ 921), fulgt i 12 år

Atrieflimmer selvrapportert med validert metode

Mozaffarian D, 2008 (11):

Hjertefrisk eldre normalbefolkning $\geq 65$ år

( $=5$ 446), fulgt i 12 år

Atrieflimmer identifisert ved EKG, Holtermonitor, journaler og utskrivningsdiagnoser
Andel

menn (\%) Mål for fysisk aktivitet

100

Spørreskjema om mengde intens trening/uke, type aktivitet og distanse hvis løping

42 Spørreskjema om mosjonsmengde,
intensitet og gangdistanse
Relativ risiko (RR) $(95 \% \mathrm{KI})$

RR 1,2 (1,0-1,4) ved daglig intens versus ingen trening

< 50 år: RR 1,7 (1,2-2,5) ved daglig intens versus ingen trening

Gradert lavere risiko for atrieflimmer ved lett til moderat intens mosjon (gange) enn ved ingen mosjon Intens mosjon: som hos de sedate lighet og økt risiko for hjerneslag, demens og hjertesvikt. Totalt ligger tilstanden bak omtrent $15 \%$ av hjerneslagstilfellene (1). I dag anses hjerneslagsrisikoen å være uavhengig av om sykdommen er permanent eller paroksystisk, men den er lav $(1,3 \%$ de neste 15 årene) hos personer under 60 år med atrieflimmer som eneste risikofaktor for slag (1).

«Fysisk aktivitet» er et vidt begrep - det omfatter kroppsbevegelse på alle nivåer av intensitet og på alle livets arenaer (4). «Trening» er definert som planlagt, strukturert og gjentatt fysisk aktivitet for å oppnå forbedring av fysisk form (4). Mange studier gjelder idrettsutøvere og atrieflimmer av type paroksystisk flimmer uten annen kardiovaskulær sykdom (5). Flimmeranfall hos mennesker som trener kommer i typiske tilfeller om natten eller etter et måltid, sjeldnere under selve aktiviteten (5). Dette forklarer at de rammede selv ikke alltid forbinder sine symptomer med trening.

Parallelt med at daglig- og arbeidslivet krever stadig mindre fysisk aktivitet, velger mange å skaffe seg mosjon i form av mer intens trening. Intervalltrening, med sikte på økt maksimal oksygenkapasitet, drives av mange og utprøves også i grupper med etablerte risikofaktorer for atrieflimmer (6). Dermed er spørsmålet om man kan «trene på seg flimmer» aktuelt også for andre enn dem som driver konkurranseidrett, selv om de sistnevnte har vært mest i søkelyset (2). Kunnskap om en mulig sammenheng mellom fysisk aktivitet og atrieflimmer er viktig også for samfunnet, med tanke på at selv en liten økning i risikoen kan ha stor betydning for sykeligheten dersom store deler av befolkningen er under risiko. Vi ønsket derfor å se nærmere på kunnskapsgrunnlaget for hypotesen om at det er en sammenheng mellom fysisk trening og atrieflimmer.

\section{Materiale og metode}

Vi søkte i PubMed på «atrial fibrillation» kombinert med hvert av søkeordene «physical activity», «endurance training», «physical exercise», «sport» og «athlete» avgrenset til perioden 1995 - mars 2011. Disse søkeordene førte i stor grad til de samme artiklene
- to oversiktsartikler, en metaanalyse, i alt 17 enkeltstudier og flere kommentarartikler og leserinnlegg. Vi tok for oss alle enkeltstudier og også nyere oversiktsarbeider (2009 - mars 2011) med mulig relevans for vår problemstilling. Etter at minst to personer hadde lest hver artikkel og en påfølgende diskusjon, ekskluderte vi sju artikler som bygde på meget små materialer, blant disse tverrsnittsstudier som kan representere en seleksjon av fullkomment friske eliteidrettsutøvere, og studier vi av andre grunner fant lite egnet til å belyse spørsmålet om sammenheng mellom fysisk aktivitet og atrieflimmer.

\section{Resultater}

Søkene våre viste at det i tiden 2009 - mars 2011 var publisert to litteraturstudier $(7,8)$ og en metaanalyse der prevalensen av atrieflimmer hos mennesker som trente ble sammenliknet med prevalensen i ulike kontrollgrupper (9). Disse arbeidene konkluderte alle med at det var forhøyet risiko for atrieflimmer hos idrettsutøvere og andre som trente regelmessig. I metaanalysen var det en total oddsratio (OR) på 5,3 (95\% konfidensintervall (KI) 3,6-7,9) (9). Disse tre artiklene inkluderte i stor grad de samme originalstudiene, av disse var det to som vi ekskluderte av metodologiske årsaker. Vår litteraturstudie omfatter ti studier. Hovedresultatene fra de sju viktigste studiene presenteres i tabeller gruppert etter design, de øvrige studiene omtales i teksten.

Tabell $1(10,11)$ viser alder og kjønn, endepunkter og hovedfunn i undersøkelser om fysisk aktivitet og atrieflimmer i store kohortstudier der det hos deltakerne er stor variasjon i fysisk aktivitet. Et arbeid, basert på Physicians' Health Study, inkluderte hjertefriske mannlige leger i alder 40-84 år (10). Man benyttet validerte spørreskjemaer om både trening og atrieflimmer, og oppfølgingstiden var 12 år. Referansegruppen besto av de nær $40 \%$ av legene som ikke mosjonerte regelmessig. Resultatene for aldersgruppen under 50 år viste at de som drev intens trening (som forte til svetting) fem til sju dager i uken, hadde større risiko for atrieflimmer (relativ risiko (RR) 1,7 (95\% KI $1,2-2,5)$ ) enn de inaktive. Hos de eldre var det liten eller ingen tendens i denne retningen. Imidlertid fant man i hele materialet at jogging fem til sju ganger i uken var forbundet med økt risiko for atrieflimmer (RR 1,5; $95 \% \mathrm{KI} 1,1-2,1)$ sammenliknet med ingen intens trening. For joggerne økte risikoen med distansen de vanligvis jogget. Det var derimot ingen økt risiko ved intens trening $\mathrm{i}$ form av svømming, sykling eller tennis.

En tilnærmet befolkningsbasert kohortstudie inkluderte eldre kvinner og menn (> 65 år, gjennomsnittsalder 73 år) trukket ut fra Medicare-lister (11). Totalt 5446 personer uten atrieflimmer ble inkludert. Disse hadde besvart Minnesota leisure-time physical activity questionnaire, et validert spørreskjema som omfatter intensitet, frekvens og varighet av ulike typer fysisk aktivitet. For hvert av nivåene for fysisk aktivitet er det oppgitt beregnet energibruk, som varierer fra $\mathrm{i}<35 \mathrm{kcal} /$ uke hos de minst aktive til i gjennomsnitt $>1840 \mathrm{kcal} /$ uke hos de mest aktive. Atrieflimmer ble identifisert ti år senere ved hjelp av EKG-undersøkelse og gjennomgang av journaler. Laveste hasardratio (HR) 0,7 (95\% KI: 0,6-0,9) ble funnet hos dem som drev mosjon i form av gange i moderat tempo - gangdistanse var inverst forbundet med risiko. De som drev mer intens trening, kom omtrent likt ut som de mest sedate. Man fant ingen effektmodifisering av kjønn, alder eller annen hjertesykdom (tab 1).

En mulig sammenheng mellom arbeidsrelatert fysisk aktivitet og atrieflimmer ble undersøkt i en befolkningsbasert dansk kohortstudie med kvinner og menn i alderen 50-65 år (12). Kohorten ble fulgt i i gjennomsnitt 5,7 år, og atrieflimmer ble identifisert gjennom et pasientregister. I forhold til sittende arbeid fant man ingen økt risiko for atrieflimmer ved «lett stående eller gående arbeid», ved «arbeid som krever at man bærer lettere gjenstander og går mye, også i trapper» eller ved «tungt kroppsarbeid» (ikke vist i tabell).

Tabell $2(13,14)$ viser hovedresultater i de to studiene med pasient-kontroll-design. En spansk studie omfattet 51 menn med atrieflimmer via journalgjennomgang $i$ en arytmipoliklinikk (13). Mennene var under 65 år gamle og i gjennomsnitt 43 år. Deres fysiske 
Tabell 2 Fysisk aktivitet og atrieflimmer i pasient-kontroll-studier

Studie (førsteforfatter, år)

\section{Elosua R, 2006 (13):}

Trening hos 51 pasienter < 65 år med atrieflimmer uten annen kardiovaskulær sykdom versus 109

kontrollpersoner fra helseundersøkelse i befolkningen

Atrieflimmer identifisert ved poliklinikk

Mont L, 2008 (14):

Trening hos 107 pasienter < 65 år med atrieflim mer uten annen kardiovaskulær sykdom versus 107 friske pårørende

Atrieflimmer identifisert ved akuttmottak

\section{Andel}

menn (\%) Mål for fysisk aktivitet

100

Spørreskjema om nåværende og tidligere fysisk aktivitet

69 Spørreskjema om tidligere fysisk aktivitet $i$ arbeid og fritid
Oddsratio (OR) (95\% KI)

OR 2,9 (1,2-6,9) for atrieflimmer uten annen kardiovaskulær sykdom ved nåværende idrettslig aktivitet (minst 2 ganger og minst 2 timer/uke) og totalt > 1500 timer idrettslig aktivitet gjennom livet versus ikke aktiv nå og totalt aktiv $<1500$ timer

OR $22,9(4,3-121,2)$ ved total moderat intens fysisk aktivitet $\geq 6626$ timer versus $0-138$ timer, OR 7,31 $(2,3-22,9)$ ved total intens fysisk aktivitet $\geq 564$ timer versus ingen intens fysisk aktivitet aktivitet ble sammenliknet med aktiviteten til 109 kontrollpersoner fra normalbefolkningen ved bruk av et ikke-validert spørreskjema om nåværende og tidligere fysisk aktivitet gjennom livet. I analysene ble det kontrollert for alder, hypertensjon og høyde. Forfatterne antyder en mulig terskelverdi for utvikling av atrieflimmer på omkring 1500 treningstimer i løpet av livet (tab 2).

I en annen pasient-kontroll-studie ble det rekruttert 107 pasienter med atrieflimmer uten annen kjent kardiovaskulær sykdom med varighet $<48$ timer for det aktuelle anfallet og alder $<65$ år (gjennomsnitt 48 år) fra et akuttmottak (14). Det fysiske aktivitetsnivået hos disse ble sammenliknet med nivået hos 107 friske frivillige kontrollpersoner rekruttert blant deres slektninger og besøkende. Fysisk aktivitet ble målt med et spørreskjema som dekket arbeid og fritid, treningsintensitet og fysisk aktivitet tilbake i tid gjennom livet. Pasientene kom ut med betydelig høyere antall timer som fysisk aktive med moderat og høy intensitet, spesielt på fritiden.

Tabell 3 (15-17) viser studier som belyser forekomsten av atrieflimmer hos konkurranseidrettsutøvere på høyt nivå. En studie inkluderte 262 mannlige orienteringsløpere (15). Disse ble sammenliknet med jevnaldrende menn som var funnet militært tjenestedyktige. Oppfølgingstiden var ti år. I alt fikk 14 orienteringsløpere atrieflimmer - prevalensen var 4,2 \% i alderen 46-54 år, $5,6 \%$ i alderen $55-62$ år og 6,6\% i alderen 63-70 år. Sammenliknet med rekruttene hadde løperne økt risiko for atrieflimmer (OR 5,5: $95 \%$ KI: 1,3-24,4). I gjennomsnitt hadde løperne med atrieflimmer trent regelmessig i 36 år, og første anfall kom rundt 52 års alder (15). Orienteringsløperne hadde imidlertid lavere dødelighet enn kontrollgruppen $(1,7 \%$ versus $8,5 \%)$ og lavere forekomst av koronar hjertesykdom i oppfølgingstiden (15).

For 78 menn med gjentatte gode resultater i Birkebeinerrennet fant Grimsmo og medarbeidere etter 28-30 års oppfølging 11 tilfeller av atrieflimmer, hvorav ti uten annen kardiovaskulær sykdom (16). Aldersspredningen ved oppfølgingen var 54-92 år i denne studien. På den annen side fant Bjørnstad og medarbeidere ingen tilfeller av atrieflimmer blant 30 tidligere eliteutøvere i langrenn, skiskyting, langdistanseløp, terrengløp og orienteringsløp etter oppfølging i 14-15 år (18). Disse utøverne, i gjennomsnitt 39 år ved oppfølgingstidspunktet, hadde endret mosjonsvaner etter avsluttet idrettskarriere 5-12 år før undersøkelsen, men det går ikke frem hvor mye og hvor intenst de hadde mosjonert de siste årene.

I en spansk studie sammenliknet man forekomsten av atrieflimmer hos 252 mannlige maratonløpere (gjennomsnittsalder 39 år) og 305 sedate menn (gjennomsnittsalder 50 år) rekruttert fra normalbefolkningen (17). Disse besvarte en validert versjon av Minnesota leisure-time physical activity

Tabell 3 Studier av forekomst av atrieflimmer hos mannlige idrettsutøvere

\section{Studie (førsteforfatter, år)}

\section{Karjalainen J, 1998 (15):}

Kohort av 262 idrettsmenn sammenliknet

med rekrutter, fulgt ti år

Atrieflimmer identifisert ved spørreskjema

\section{Grimsmo J, 2010 (16):}

Kohort av 78 «birkebeinere» fulgt 1976-81 til 2004-06

Atrieflimmer identifisert ved klinisk undersøkelse,

EKG og ekkokardiografi

\section{Molina L, 2008 (17):}

Retrospektiv kohort, 252 mannlige løpere sammenliknet med 305 sedate menn fra generell befolkning, fulgt i hhv. 11,6 og 6,4 år

EKG og ekkokardiografi

Skiløping, høyt mosjonsnivå i mange år

Type fysisk aktivitet

Orientering, høyt nivå i mange år

Atrie-

flimmer $(n)^{1}$ Risikoestimat (95\% KI)

14

Maraton på mosjonsnivå
OR 5,5 (1,3-24,4) for atrieflimmer hos idrettsmenn versus rekrutter

${ }^{1}$ Antall tilfeller blant idrettsutøverne 
questionnaire. Maratonløperne ble fulgt i i gjennomsnitt 11,6 år, kontrollgruppen i 6,4 år. I alt 11 tilfeller av paroksystisk eller persistent atrieflimmer uten annen kardiovaskulær sykdom oppsto, hos ni løpere og to i kontrollgruppen (17). I et materiale av 62 tidligere profesjonelle syklister (gjennomsnittsalder 66 år) ble det funnet en overhyppighet av atrieflimmer i forhold til tilstanden hos 62 jevnaldrende golfspillere (19). I denne studien ble deltakerne spurt om bruk av prestasjonsfremmende medikamenter, noe 44 av de 62 syklistene hadde brukt, oftest i form av amfetamin eller anabole steroider.

\section{Diskusjon}

Konklusjonen i de fleste studiene vi har gjennomgått, etterlater et inntrykk av at intens utholdenhetstrening gjennom flere tiår øker risikoen for atrieflimmer, i det minste hos menn etter 40 års alder. Ingen av studiene som inkluderer mindre intens mosjon, som for eksempel det å gå, antyder at dette gir økt risiko. Kan vi stole på disse resultatene?

\section{Feilkilder som må tas i betraktning}

Alle de siterte undersøkelsene er observasjonsstudier. Dette innebærer minst tre kilder til feilslutning: seleksjonsskjevhet, informasjonsskjevhet og forekomst av konfunderende faktorer. Seleksjon ut fra alder, som innebærer både biologisk aldring, samlet eksposisjon for fysisk aktivitet og samlet eksposisjon for andre risikofaktorer for atrieflimmer, blir viktig i studier av tilstanden (1). Høy nedre aldersgrense for inklusjon, som i studien basert på Medicare-listene (11), kan medføre at en del personer med treningsrelatert atrieflimmer blir ekskludert som syke ved inklusjonen, slik at man får en «healthy worker»-effekt. De som har atrieflimmer eller liknende symptomer kan også ha sluttet å trene før inklusjonen. At Bjørnstad og medarbeidere ikke fant tilfeller av atrieflimmer, $i$ en studie med gjennomsnittsalder på 39 år ved oppfølgingens slutt (18), kan skyldes tilfeldighet eller deltakernes unge alder.

De over 16000 deltakerne i Physician's Health Study (10) stammer fra en utgangspopulasjon på over 200000 leger. Generelt behøver ikke seleksjonsprosesser påvirke effektestimatene, men i denne studien vet vi ikke om frafallet var selektivt med henblikk på fysisk aktivitet eller atrieflimmer. Studier basert på kliniske materialer er utsatt for seleksjonsskjevhet ved at det ikke er tilfeldig hvilke pasienter som blir utredet ved den enkelte klinikk $(13,14)$. I flere av studiene kan det også tenkes å være seleksjonsskjevhet i kontrollgruppene $(13-15,17,19)$.

Det foreligger informasjonsskjevhet når registreringen av endepunktet har sammenheng med eksponeringen man studerer. I retrospektive pasient-kontroll-studier (13, 14) kan det tenkes at personer med atrieflimmer husker treningen opp gjennom årene bedre enn de friske kontrollpersonene gjør. Dette kan slå sterkt ut når man spør om tre- ning langt tilbake i tid, slik man gjorde i disse studiene $(13,14)$. Når pårørende er brukt som kontrollpersoner (14), må man i særlig grad kunne stille spørsmål om informasjonsskjevhet. Det kan videre tenkes at de som trener hardt, i særlig grad er kroppsbevisste og plaget av symptomer og derfor vil være spesielt tilbøyelige til å søke hjelp og få registrert atrieflimmer. Det kan imidlertid også tenkes at disse unnlater å søke lege for å unngå sykdomsstempel og medikamenter, spesielt ved sjeldne anfall og lite plagsom atrieflimmer, og eventuelt heller velger å redusere treningsmengden og -intensiteten.

I observasjonsstudier forsøker man å kontrollere for såkalt konfunderende faktorer, som her består $i$ at fysisk aktivitet kan henge sammen med andre forhold som, uavhengig av den fysiske aktiviteten, kan påvirke risikoen for atrieflimmer. Annen hjerte- og karsykdom, diabetes, overvekt og stoffskiftelidelse vil kunne påvirke (oftest hemme) den fysiske aktiviteten og øker i seg selv risikoen for lidelsen (1). Dette vil, spesielt hos eldre, kunne slå ut i retning av negativ sammenheng mellom fysisk aktivitet og atrieflimmer. Flere av studiene vi gjennomgikk, inkluderte klinisk undersøkelse og kan ha god kontroll for sykdom, mens andre kun er basert på egenrapportering av sykdom (10, 12) eller det mangler informasjon (15).

Høyde og kroppsmasseindeks $(14,20)$, og også regelmessig alkoholinntak (21), er nå etablerte risikofaktorer for atrieflimmer. I en metaanalyse av 14 studier fant man at alkoholbruk spesielt er forbundet med paroksystisk atrieflimmer uten annen kardiovaskulær sykdom, og resultatene tydet på en gradert økning i risiko fra relativt lavt daglig inntak av alkohol (21). Av studiene vi har gjennomgått, er det bare de store kohortstudiene $(10-12)$ og den spanske studien av maratonløpere (17) som inneholder systematisk informasjon om disse faktorene. I andre studier er informasjonen om mulig konfunderende faktorer sparsom eller fraværende (14, 15), og noen studier hadde også andre metodologiske svakheter $(13,14,17,19)$.

Betydningen av prestasjonsfremmende medikamenter som årsak til atrieflimmer er utilstrekkelig kjent (1). Det er mulig at fysiologiske nivåer og lavdosert tilskudd av testosteron virker beskyttende, mens det ser ut til at anabole steroider i større doser kan gi økt risiko (22). I en av studiene vi gjennomgikk, var det informasjon om bruk av anabole steroider (19), men vi har ikke funnet studier det man har kunnet kontrollere for slik informasjon $\mathrm{i}$ analysen.

\section{Inflammasjon - ledd i en årsakskjede?}

En sammenheng mellom trening og atrieflimmer kan tenkes forklart ved en kombinert effekt av økt sympatikustonus og volumbelastning på hjertet under selve aktiviteten, økt vagustonus i hvile og strukturelle endringer som hypertrofi og dilatasjon (1). Det kan tenkes at myokarditt og perikarditt gir økt risiko for atrieflimmer direkte ved å frembringe strukturelle endringer mens infeksjonen pågår og ved autoimmun reaksjon i etterkant (23). De som trener mye, kan være særlig utsatt for infeksjoner som affiserer sirkulasjonsorganene, og kan hende trener de også under pågående infeksjon. Det er påvist sammenheng mellom inflammasjonsmarkører i blod og forekomst av atrieflimmer etter 14 års oppfølging (24), noe som kan støtte en inflammasjonshypotese. Det er imidlertid også vist at moderat fysisk trening kan reversere inflammasjon hos eldre (25).

\section{Konklusjon}

Det er overbevisende dokumentert at regelmessig fysisk aktivitet, ikke minst intens utholdenhetstrening, forebygger tidlig død (26) og koronar hjertesykdom $(26,27)$. Denne litteraturstudien gir imidlertid støtte for hypotesen om at intens utholdenhetstrening gjennom mange år kan gi økt risiko for atrieflimmer. Hittil finnes det ingen studier der man har funnet tegn på at mindre intens fysisk aktivitet øker risikoen.

Flere av studiene vi har inkludert, har imidlertid metodologiske svakheter, og resultatene må tolkes med forsiktighet. To oversiktsartikler $(7,8)$ inkluderte to studier basert på det samme materialet, 51 menn med atrieflimmer uten annen kardiovaskulær sykdom (vår referanse $13 \mathrm{og}$ en eldre studie som ikke er inkludert av oss). Dette kan være et eksempel på at et forskningsfelt drives mot publikasjonsskjevhet og overestimering av sammenhengen som studeres (28). Videre er studiene vi har gjennomgått ikke direkte sammenliknbare fordi de varierer når det gjelder definisjonen av fysisk aktivitet og atrieflimmer. Det er også stor variasjon $i$ alder.

De fleste studiedeltakerne er menn, og det er ikke grunnlag for å slutte noe om effekten av fysisk trening på utviklingen av atrieflimmer hos kvinner. Antallet kvinner som trener kan ha vært for lavt i studiene som er gjort frem til nå. Det er behov for oppfølgingsstudier som inkluderer unge mennesker, slik at betydningen av alder kan bli belyst. I nye studier der man vil belyse en mulig sammenheng mellom fysisk aktivitet og atrieflimmer, bør man se nærmere på treningsfrekvens, varighet og intensitet og på det samlede treningsvolumet.

Vi vet ikke om kortvarig høyintensiv intervalltrening medfører større risiko enn langkjøring med lavere intensitet og større samlet treningsvolum. Studien som antyder en terskelverdi på 1500 timer intens trening i løpet av livet, tilsvarende to timer i uken i 15 år, bør følges opp av større og metodologisk sterkere studier. Det bør også settes søkelys på genetisk sårbarhet, og det er viktig å ha kontroll for andre risikofaktorer enn fysisk aktivitet, som høyde, kroppsmasseindeks, alkoholbruk, stoffskiftesykdom, høyt blodtrykk og annen hjerte- og karsykdom. Og - kanskje viktigst - kvinner må inkluderes. 


\section{Sidsel Graff-Iversen (f. 1948)}

er tidligere spesialist i allmennmedisin. Hun arbeider nå innen epidemiologisk forskning og undervisning i forebyggende medisin. Ingen oppgitte interessekonflikter.

\section{Knut Gjesdal (f. 1944)}

er professor og spesialist i indremedisin og i hjertesykdommer. Han arbeider som professor og overlege ved Kardiologisk avdeling, Oslo universitetssykehus, Ullevål. Ingen oppgitte interessekonflikter.

\section{Astanand Jugessur f. 1972}

er dr.scient. i genetisk epidemiologi. Etter to postdoktorperioder i USA og Australia jobber han i dag som forsker ved Nasjonalt folkehelseinstitutt.

Ingen oppgitte interessekonflikter.

\section{Marius Myrstad (f. 1978)}

er lege i spesialisering i indremedisin og i geriatri ved Diakonhjemmet Sykehus. Ingen oppgitte interessekonflikter.

\section{Wenche Nystad}

er ph.d. og avdelingsdirektør ved Avdeling for folkesykdommer, Divisjon for epidemiologi, Nasjonalt folkehelseinstitutt.

Ingen oppgitte interessekonflikter.

\section{Randi Selmer (f. 1953)}

er dr.philos., statistiker og seniorforsker ved Divisjon for epidemiologi, Folkehelseinstituttet. Ingen oppgitte interessekonflikter.

\section{Dag S. Thelle (f. 1942)}

er spesialist i indremedisin, professor i epidemiologi og inngår i forskergruppen for epidemiologiske og statistiske metoder, Institutt for medisinske basalfag ved Universitetet i Oslo. Han er tidligere overlege og professor i preventiv kardiologi ved Sahlgrenska Universitetssjukhuset, Göteborg, og medansvarlig for planlegging og gjennomføring av flere epidemiologiske studier i Nord-Norge i regi av Universitetet i Tromsø.

Ingen oppgitte interessekonflikter.

\section{Litteratur}

1. Camm AJ, Kirchhof P, Lip GY et al. Guidelines for the management of atrial fibrillation: the Task Force for the Management of Atrial Fibrillation of the European Society of Cardiology (ESC). Europace 2010; 12: $1360-420$

2. Thelle DS, Løchen ML. Kaotiske hjerter. Atrieflimmer - en moderne epidemi. Oslo: Gyldendal Akademisk, 2010

3. Tveit $A$, Abdelnoor $M$, Enger $S$ et al. Atrial fibrillation and antithrombotic therapy in a 75-year-old population. Cardiology 2008; 109: 258-62.

4. Caspersen CJ, Powell KE, Christenson GM. Physical activity, exercise, and physical fitness: definitions and distinctions for health-related research. Public Health Rep 1985; 100: 126-31.

5. Mont L. Arrhythmias and sport practice. Heart 2010; 96: 398-405.

6. Ingul CB, Tiønna AE, Stølen TO et al. Impaired cardiac function among obese adolescents: effect of aerobic interval training. Arch Pediatr Adolesc Med 2010; 164: 852-9.

7. Mont L, Elosua R Brugada J. Endurance sport practice as a risk factor for atrial fibrillation and atrial flutter. Europace 2009; 11: 11-7.

8. Sorokin AV, Araujo CG, Zweibel $S$ et al. Atrial fibrillation in endurance-trained athletes. $\mathrm{Br} \mathrm{J}$ Sports Med 2011: 45: 185-8.

9. Abdulla J, Nielsen JR. Is the risk of atrial fibrillation higher in athletes than in the general population? A systematic review and meta-analysis. Europace 2009; 11: 1156-9.

10. Aizer A, Gaziano JM, Cook NR et al. Relation of vigorous exercise to risk of atrial fibrillation. Am J Cardiol 2009; 103: 1572-7.

11. Mozaffarian D, Furberg CD, Psaty BM et al. Physical activity and incidence of atrial fibrillation in older adults: the cardiovascular health study. Circulation 2008; 118: 800-7.

12. Frost $L$, Frost $P$, Vestergaard $P$. Work related physical activity and risk of a hospital discharge diagnosis of atrial fibrillation or flutter: the Danish Diet, Cancer, and Health Study. Occup Environ Med 2005; 62: 49-53.

13. Elosua R, Arquer A, Mont L et al. Sport practice and the risk of lone atrial fibrillation: a case-control study. Int J Cardiol 2006; 108: 332-7.

14. Mont L, Tamborero D, Elosua R et al. Physical activity, height, and left atrial size are independent risk factors for lone atrial fibrillation in middle-aged healthy individuals. Europace 2008; 10: 15-20.

15. Karjalainen J, Kujala UM, Kaprio J et al. Lone atria fibrillation in vigorously exercising middle aged men: case-control study. BMJ 1998; 316: 1784-5

16. Grimsmo J, Grundvold I, Maehlum S et al. High prevalence of atrial fibrillation in long-term endurance cross-country skiers: echocardiographic findings and possible predictors-a $28-30$ years follow-up study. Eur J Cardiovasc Prev Rehabil 2010: 17: 100-5

17. Molina L, Mont L, Marrugat J et al. Long-term endurance sport practice increases the incidence of lone atrial fibrillation in men: a follow-up study. Europace 2008; 10: 618-23.
18. Bjørnstad HH, Bjørnstad TH, Urheim S et al. Longterm assessment of electrocardiographic and echocardiographic findings in Norwegian elite endurance athletes. Cardiology 2009; 112: 234-41.

19. Baldersberger S, Bauersfeld U, Candinas R et al. Sinus node disease and arrhytmias in the longterm follow-up of former prfessional cyclistis. Eur Heart J 2008; 29: 71-8.

20. Rosengren A, Hauptman PJ, Lappas $G$ et al. Big men and atrial fibrillation: effects of body size and weight gain on risk of atrial fibrillation in men. Eur Heart J 2009; 30: 1113-20.

21. Kodama S, Saito K, Tanaka S et al. Alcohol consumption and risk of atrial fibrillation: a metaanalysis. J Am Coll Cardiol 2011; 57: 427-36.

22. Liu T, Shehata M, Li G et al. Androgens and atrial fibrillation: friends or foes? Int J Cardiol 2010; 145: $365-7$

23. Korantzopoulos P, Liu T, Milionis HJ et al. 'Lone' atrial fibrillation: hunting for the underlying causes and links. Int J Cardiol 2009; 131: 180-5.

24. Conen D, Ridker PM, Everett BM et al. A multimarker approach to assess the influence of inflammation on the incidence of atrial fibrillation in women Eur Heart J 2010; 31: 1730-6.

25. Nicklas BJ, Brinkley TE. Exercise training as a treatment for chronic inflammation in the elderly. Exerc Sport Sci Rev 2009: 37: 165-70.

26. Schnohr P, Marott JL, Jensen JS et al. Intensity versus duration of cycling, impact on all-cause and coronary heart disease mortality: the Copenhagen City Heart Study. Eur Cardiovasc Prev Rehabil 2011: e-publisert 21.2.

27. Sattelmair J, Pertman J, Ding EL et al. Dose response between physical activity and risk of coronary heart disease: a meta-analysis. Circulation 2011: 124: 789-95.

28. Ioannidis JP. Why most published research findings are false. PLoS Med 2005; 2: e124.

Mottatt 16.5. 2011, første revisjon innsendt 7.10. 2011, godkjent 3.11. 2011. Medisinsk redaktør Jon Amund Kyte. 